\title{
Comparison of Conventional Methods and Laser-Assisted Rapid Prototyping for Manufacturing Fixed Dental Prostheses: An In Vitro Study
}

\author{
Giorgio Pompa, ${ }^{1}$ Stefano Di Carlo, ${ }^{1}$ Francesca De Angelis, ${ }^{1}$ \\ Maria Paola Cristalli, ${ }^{2}$ and Susanna Annibali ${ }^{1}$ \\ ${ }^{1}$ Department of Oral and Maxillofacial Sciences, "Sapienza” University of Rome, 00161 Rome, Italy \\ ${ }^{2}$ Department of Medico-Surgical Sciences and Biotechnologies, "Sapienza" University of Rome, 00161 Rome, Italy \\ Correspondence should be addressed to Susanna Annibali; susanna.annibali@uniroma1.it
}

Received 11 November 2014; Accepted 21 January 2015

Academic Editor: Hamit S. Çötert

Copyright (C) 2015 Giorgio Pompa et al. This is an open access article distributed under the Creative Commons Attribution License, which permits unrestricted use, distribution, and reproduction in any medium, provided the original work is properly cited.

This study assessed whether there are differences in marginal fit between laser-fusion and conventional techniques to produce fixed dental prostheses (FDPs). A master steel die with 2 abutments was produced to receive a posterior 4-unit FDPs and single copings. These experimental models were divided into three groups ( $n=20$ /group) manufactured: group 1 , Ni-Cr alloy, with a lost-wax casting technique; group 2, Co-Cr alloy, with selective laser melting (SLM); and group 3, yttria-tetragonal zirconia polycrystal (Y-TZP), with a milling system. All specimens were cut along the longitudinal axis and their adaptation was measured at the marginal and shoulder areas on the right and left sides of each abutment. Measurements were made using a stereomicroscope ( $\times 60$ magnification) and a scanning electron microscope $(\times 800$ magnification). The data were analyzed using one-way analysis of variance and the Bonferroni post hoc test, with a significance cutoff of $5 \%$. Significant differences $(P<0.05)$ were observed between group 3 and the other groups. The marginal opening was smallest with $\mathrm{Co}$-Cr alloy substructures, while the shoulder opening was smallest with $\mathrm{Ni}-\mathrm{Cr}$ alloy substructures. Within the limitations of this study, the marginal fit of an FDP is better with rapid prototyping $(\mathrm{RP})$ via SLM than conventional manufacturing systems.

\section{Introduction}

Fixed dental prostheses (FDPs) are the rehabilitation of choice after endodontic and operative treatments, especially among all over the world [1]. Moreover, the introduction of implant restorations has increased the popularity of fabricating crowns and bridges to rehabilitate the edentulous area. The development of both casting gold alloys and dental precision casting systems has contributed to the application of metallic restorations. However, patients are increasingly requesting metal-free restorations for aesthetics and biosafety reasons [2].

A poor marginal fit of crowns is responsible for $10 \%$ of prosthetic failures; these failures are mainly due to secondary caries, periodontal diseases, pulpitis, necrosis, and technical errors $[3,4]$. Clinical trials have demonstrated the importance of the marginal fit in the quality assessment of fixed restorations and for their clinical success [5]. There are various opinions about the required marginal fit in the literature [69], but gaps of $100-150 \mu \mathrm{m}$ are generally considered to be clinically acceptable $[8,10-14]$. The marginal fit of FDPs is a fundamental requirement $[15,16]$ to achieve a clinically acceptable result with a good long-term prognosis [17-20].

Noble-metal alloys are generally preferred to base-metal alloys for the manufacture of FDPs due to their biocompatibility, good mechanical properties, and excellent ceramicmetal bonding [21]. However, nonprecious alloys, such as nickel-chromium (Ni-Cr) and cobalt-chromium (Co-Cr), are now commonly used for the substructure of metalceramic restorations due to economic considerations [22, 23]. The trend in modern dentistry is to use metal-free restorations, but metal-ceramic crowns are still the most 
TABLE 1: Composition and properties of materials used and their manufacturing processes.

\begin{tabular}{|c|c|c|c|c|c|c|}
\hline Product & Process & $\begin{array}{c}\text { Alloy composition } \\
\text { (Wt \%) }\end{array}$ & $\begin{array}{c}\text { Elastic modulus } \\
(\mathrm{GPa})\end{array}$ & $\begin{array}{c}\text { Vickers } \\
\text { hardness } \\
\left(\mathrm{Kg} / \mathrm{mm}^{2}\right)\end{array}$ & $\begin{array}{c}\text { Yield strength } \\
(\mathrm{MPa}, 0.2 \%)\end{array}$ & $\begin{array}{c}\text { Thermal expansion } \\
\text { coefficient } \\
10^{-6} \mu \mathrm{m} / \mathrm{mK} \\
\left(25-500^{\circ} \mathrm{C}\right)\end{array}$ \\
\hline $\begin{array}{l}\text { Cercon base } \\
\text { (DeguDent) } \\
\text { Ni-Cr alloy }\end{array}$ & Lost wax casting & $\begin{array}{c}\text { Co } 0.1 \\
\text { Cr 14-16 } \\
\text { Al 1-3 } \\
\text { Ni } 71-75 \\
\text { Mo 8-10 } \\
\text { Be 0.1-1.9 } \\
\text { Traces of Ti } \\
\end{array}$ & 218 & 360 & 586 & 13.9 \\
\hline $\begin{array}{l}\text { StarLoy LS } \\
\text { (DeguDent) } \\
\text { Co-Cr alloy }\end{array}$ & $\begin{array}{l}\text { Selective laser } \\
\text { melting (SLM) }\end{array}$ & $\begin{array}{c}\text { Co } 55.2 \\
\text { Cr } 18.4 \\
\text { W } 18.4 \\
\text { Fe } 6.0 \\
\text { Al } 2.0 \\
\end{array}$ & 210 & 390 & $938-1024$ & 14.3 \\
\hline $\begin{array}{l}\text { Biologic NA } \\
\text { (Conero Dental) } \\
\text { Y-TZP }\end{array}$ & Milling & $\begin{array}{c}\mathrm{ZrO}_{2} \\
\mathrm{Y}_{2} \mathrm{O}_{3} 5 \% \\
\mathrm{HfO}_{2}<2 \% \\
\mathrm{Al}_{2} \mathrm{O}_{3} \text { and } \\
\mathrm{SiO}_{2}<1 \%\end{array}$ & 210 & 1200 & $900-1200$ & 10.5 \\
\hline
\end{tabular}

widely used ones due to their excellent mechanical properties and clinical performance, low cost compared to metalfree restorations, simple cementation technique, and role in natural reproduction of lost dentition in most restorative treatments [24]. The conventional technique for fabricating a metal structure is lost-wax casting. However, computer-aided design and manufacturing (CAD/CAM) technologies now allow the precise design of elements produced by specialized computerized equipment [25]. The use of CAD/CAM systems has been considered by several authors in the dentistry field, especially for the manufacture of FDPs [26-34]. Laserassisted rapid prototyping (RP) is a CAD/CAM technology that was originally developed to fabricate prototypes for industrial purposes, and the use of RP systems can reduce the sensitivity and the technical complexity involved in the creation of a dental prosthesis [35].

This in vitro study compared the internal and marginal precisions of different posterior FDPs manufactured using three different methods: a milling system, laser-assisted RP through selective laser melting (SLM), and the lost-wax casting technique. The aim was to quantify the differences in accuracy between copings produced with SLM and the other techniques so as to provide an experimental basis for clinical research. The hypothesis of the study is the objective of allowing the clinician to rely on technology in increasingly more reliable and reproducible way, with a minimum margin of error in the realization of FDPs.

\section{Materials and Methods}

In the study the following methods have been used: (1) the CAD/CAM Cercon system and the Compartis system (DeguDent, Hanau, Germany) for manufacturing Y-TZP (zirconium oxide stabilized with yttrium oxide) single copings and bridges using a milling technique, (2) SLM for

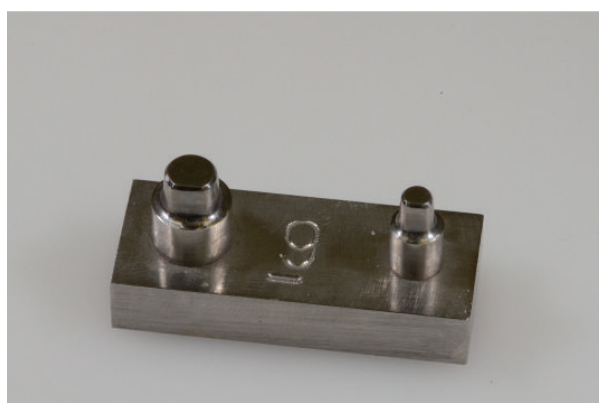

FIGURE 1: Master stainless-steel model.

Co-Cr alloy, and (3) the conventional lost-wax technique for the realization of single crowns and bridges in $\mathrm{Ni}-\mathrm{Cr}$ alloy. The compositions of the materials selected for this study and their processing techniques are provided in Table 1.

2.1. Manufacturing the Models. A stainless-steel model with two abutments simulating a first premolar and a second molar screwed tightly on a holder ( $40 \mathrm{~mm}$ long, $16 \mathrm{~mm}$ wide, and $8 \mathrm{~mm}$ thick) was machined at the Mechanical and Aerospace Department of "Sapienza" University of Rome (Figure 1).

The abutments were positioned on the platform to receive posterior four-unit FDPs or two single crowns. The preparation had a finish line with a $1.0 \mathrm{~mm}$ radius, a 10 -degree angle of convergence of the axial walls, and a shoulder margin, thereby simulating clinical conditions. A vertical flat surface parallel to the long axis of the abutments allowed the correct insertion of the structures and also ensured the stability of the platform. Specimens were measured using a digital caliper (Aura Dental, Germany) with an accuracy of $0.01 \mathrm{~mm}$. The steel sample was used as the master model, and it was duplicated using silicone (Elite Double 22, Zhermack, Germany). 


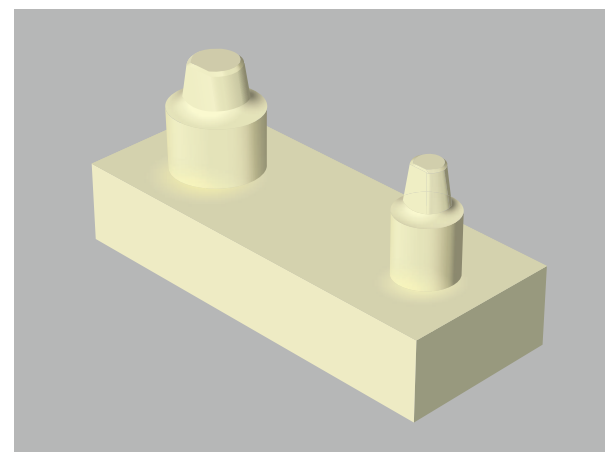

Figure 2: 3D model.

The master steel model was placed in a rigid plastic container with a top opening, and the silicone material was then poured in, with the expected hardening times following the manufacturer's instructions. Casts of polyurethane resin were then made (K.W. New Color, Techim Group), which were used as working dies. Thirty resin casts were constructed, and they were divided into three groups: group $1, \mathrm{Ni}-\mathrm{Cr}$ alloy; group 2, Co-Cr alloy; and group 3, Y-TZP. Each group comprised five resin casts for single copings and five resin casts for four-unit bridges ( $n=10$ /group). The resin casts with single copings were then dissected to analyze the copings separately. The same protocol was used for the bridges. All of the samples used in the study were marked with an identification code $(n=20)$, with 10 single structures and 10 elements of bridges being fabricated for each group.

2.2. Manufacturing the Framework. The dies for copings in the Ni-Cr alloy group were coated with a layer of die spacer (total thickness of $20 \mu \mathrm{m}$ ) applied $0.5 \mathrm{~mm}$ above the margin (Yeti Die Spacer, Yeti Dental, Engen, Germany). The NiCr alloy was cast by a private dental laboratory (SaviDent, Rome, Italy) using the conventional lost-wax technique and single casting to fabricate the restorations. Wax patterns were prepared and invested with carbon-free phosphate bonded investment material (GC Stellavest, GC Corporation, Belgium) in accordance with the manufacturer's instructions (Figure 2). The patterns were casted in $\mathrm{Ni}-\mathrm{Cr}$ alloy (Biologic NA, Conroe Dental, Ancona, Italy) using an induction and centrifugation casting machine (Seit Elettronica, Italy). After divesting, the castings were cleaned with $50 \mu \mathrm{m} \mathrm{Al}_{2} \mathrm{O}_{3}$ using an air-borne-particle abrasion device (Basic Master, Renfert, Hilzingen, Germany). Each FDP was fabricated according to the manufacturer's instructions by the same dental technician. Y-TZP samples were digitized using the 3Shape D700 scanner (3S, DeguDent), which uses a laser-based optical scanning method. The $3 \mathrm{~S}$ has a three-axis movement system that allows for an individualized scanning position of the casts. The CAD process was performed with the 3 Shape Dental System software (3Shape A/S, Copenhagen, Denmark). All copings had a minimum thickness of $0.5 \mathrm{~mm}$, which was consistent with the manufacturer's recommendation. All FDPs produced with the 3Shape system were fabricated in Y-TZP (Cercon Base, DeguDent) by a centralized milling center (Compartis, DeguDent) after transmitting the data via

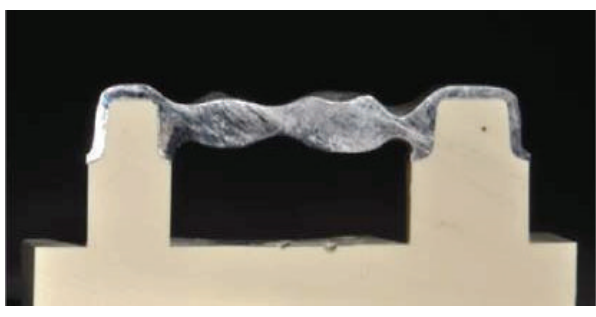

FIGURE 3: Sectioned framework.

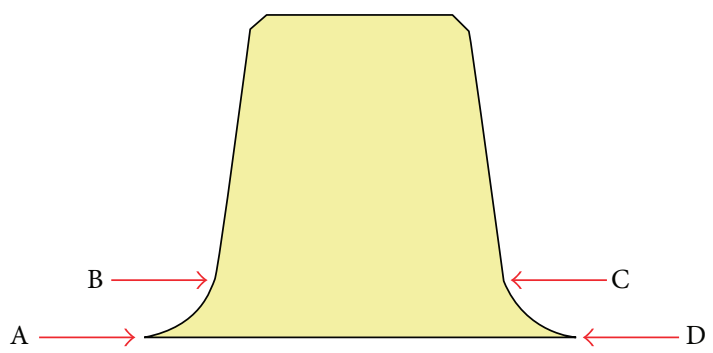

FIGURE 4: Representation of the four measuring points on each abutment.

the Internet. Co-Cr alloy (StarLoy LS, DeguDent) copings were fabricated using the SLM technique. Scanning patterns and phase CAD were performed by the same method used for the Y-TZP samples. The production of substructures was outsourced to the Compartis Center (DeguDent).

All of the structures were repositioned on their models and then checked for the correct positioning. If the positioning was incomplete, the structure was adapted using a standardized protocol according to the literature and clinical practice [35-39]. Areas to be corrected were identified by applying a spray lacquer (Contact-Spray, Protechno, Girona, Spain). The colored spots inside the cap were removed with a tungsten carbide bur while using a water spray to clean the debris. The same dental expert adapted and verified all of the restorations.

2.3. Cementation Process. All FDPs were cemented using a conventional glass ionomer (Ketac Cem Easymix, 3M ESPE, USA), mixed following the manufacturer's instructions. The cement was placed on the axial surfaces of the abutments so that cementation would simulate the clinical procedure as closely as possible.

Each restoration was set on pillars and subjected to a pressure of $50 \mathrm{~N}[8,40-43]$ for 10 minutes using a compression testing machine with automatic recognition of calibration data at $50 \mathrm{~N}$ (Mecmesin, United Kingdom).

2.4. Analyses and Measurements of Marginal Fit. At 24 hours after cementation, each framework was sectioned centrally in the mesiodistal direction (Figure 3 ) with the aid of a cutting machine (Micromet, Remet, Bologna, Italy). The fit of the substructures was evaluated as illustrated in Figure 4.

For each substructure, the four measurement locations were used to determine the precision of the marginal and 


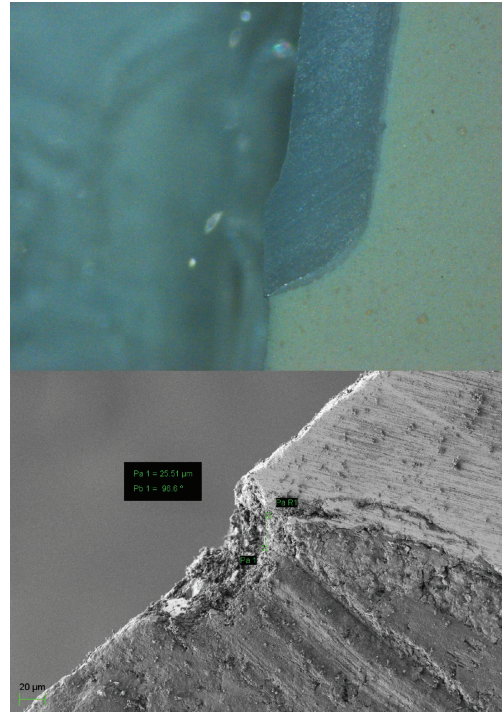

(a)

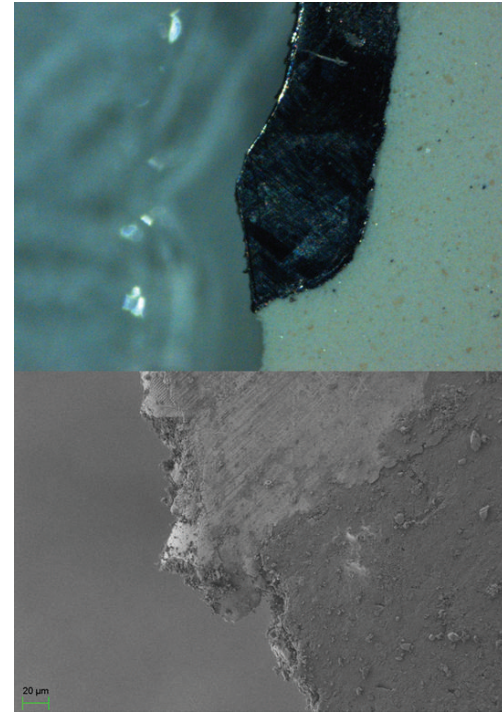

(b)

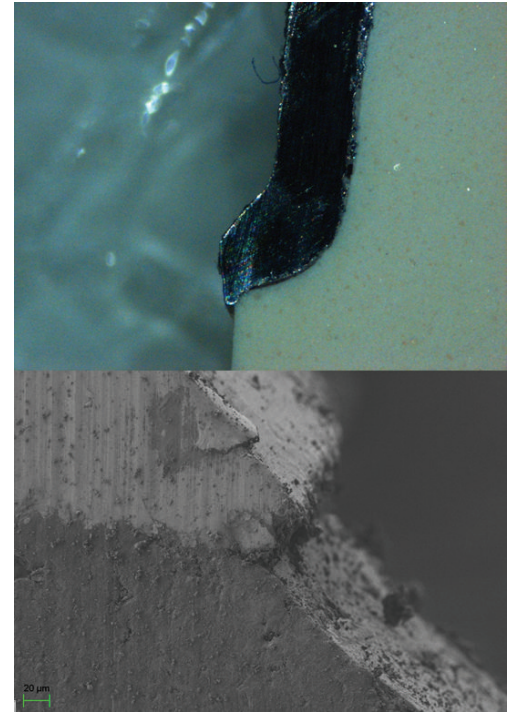

(c)

FIGURE 5: Stereomicroscope and SEM micrographs of the marginal precisions of (a) a Y-TZP premolar abutment, (b) a Co-Cr premolar abutment, and (c) an Ni-Cr alloy premolar abutment.

internal fits: the marginal opening (points $\mathrm{A}$ and $\mathrm{D}$ ), at the point of closest approximation between the model and the substructure, and the shoulder area (points B and C), corresponding to the internal adaptation of the substructure at $1 \mathrm{~mm}$ from the margin. Image analysis software (AxioVision Rel. 4.8, Zeiss, Germany) in combination with a stereomicroscope (Stemi $200-C$, Zeiss) at $\times 60$ magnification and a camera (AxioCam ICc1, Zeiss) were used for analyzing the marginal fit. The specimens were positioned in a base perpendicular to the optical axis of the microscope.

Given the thinness of the cement, additional micrographs were acquired using image analysis software (SmartSEM, Zeiss) in combination with field-emission scanning electron microscopy $($ SEM) at $\times 800$ magnification (Auriga, Zeiss) at the Nanotechnology and Nanoscience Laboratory, SNNLab, Sapienza University of Rome, which was capable of performing low-voltage imaging of highly nonconductive materials. All measurements were performed by the same investigator, and the accelerating voltage was fixed at $1 \mathrm{kV}$ (Figures 5(a), 5(b), and 5(c)) Measurements for each FDP were averaged, and these were used to determine the mean discrepancy in the marginal fit in each group $(n=20)$.

2.5. Statistical Analyses. The statistical analysis was carried out using Stata 12.0 software. Descriptive statistics included the calculation of mean $(\bar{x})$ and standard deviation (SD) values for all available measurements at each point. A oneway analysis of variance (ANOVA) was carried out to identify statistically significant differences between the investigated systems in terms of marginal fit at the different measurement locations confirmed with the nonparametric Kruskal-Wallis test. A Bonferroni post hoc test was used to compare the different groups. The cutoff for significance was set at $5 \%$ in all tests.

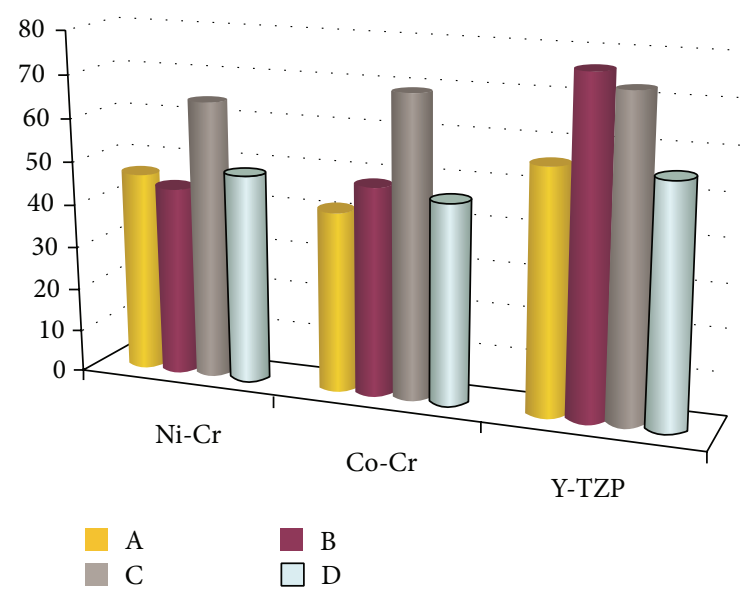

FIGURE 6: The total mean of marginal and internal discrepancies of 4 measurement points for each group (values in $\mu \mathrm{m}$ ).

\section{Results}

The mean and SD values of the marginal and internal adaptations for all measurement points, tooth sizes, and production methods are presented in Tables 2 and 3. Measurements have been made in the same locations in stereomicroscope and SEM. The mean values for all measurement points are shown in Figure 6. The discrepancies were largest in the Y-TZP group. The discrepancies in tooth size between the premolar bridge, molar bridge, single premolar, and single molar were largest between the single premolar and the premolar bridge $(P<0.05)$.

Significant differences were present for the position parameter, with higher discrepancies at points $\mathrm{A}$ and $\mathrm{B}$ 
TABLE 2: Mean values $(\bar{x})$ and standard deviation values (SD) of points A and B for all abutments in each group (values in $\mu \mathrm{m}$ ).

\begin{tabular}{|c|c|c|c|c|}
\hline Point A & $\begin{array}{c}\text { Y-TZP } \\
\bar{x}( \pm \mathrm{SD})\end{array}$ & $\begin{array}{c}\text { Co-Cr } \\
\bar{x}( \pm \mathrm{SD})\end{array}$ & $\begin{array}{c}\mathrm{Ni}-\mathrm{Cr} \\
\bar{x}( \pm \mathrm{SD})\end{array}$ & $\mathrm{pV}$ \\
\hline Premolar abutment & $51.37(10.62)$ & $43.88(15.25)$ & $48.49(15.12)$ & 0.696 \\
\hline Molar abutment & $60.88(6.56)$ & $47.06(18.96)$ & $58.92(15.20)$ & 0.302 \\
\hline Single abutment & $56.37(9.09)$ & $33.08(7.56)$ & $31.53(5.30)$ & 0.001 \\
\hline Single abutment & $56.03(5.45)$ & $43.80(17.26)$ & $43.68(21.68)$ & 0.571 \\
\hline Point B & $\begin{array}{c}\text { Y-TZP } \\
\bar{x}( \pm \mathrm{SD})\end{array}$ & $\begin{array}{c}\text { Co-Cr } \\
\bar{x}( \pm \mathrm{SD})\end{array}$ & $\begin{array}{c}\mathrm{Ni}-\mathrm{Cr} \\
\bar{x}( \pm \mathrm{SD})\end{array}$ & $\mathrm{pV}$ \\
\hline Premolar abutment & $78.62(18.25)$ & $39.61(12.90)$ & $27.23(16.18)$ & 0.001 \\
\hline Molar abutment & $75.47(20.00)$ & $73.60(24.54)$ & $69.64(20.19)$ & 0.911 \\
\hline Single abutment & $77.87(12.86)$ & $30.79(9.60)$ & $36.08(21.95)$ & 0.002 \\
\hline Single abutment & $74.25(23.33)$ & $48.65(19.06)$ & $42.07(21.52)$ & 0.181 \\
\hline
\end{tabular}

TABLE 3: Mean values $(\bar{x})$ and standard deviation values (SD) of points $\mathrm{C}$ and $\mathrm{D}$ for all abutments in each group (values in $\mu \mathrm{m}$ ).

\begin{tabular}{|c|c|c|c|c|}
\hline Point C & $\begin{array}{c}\mathrm{Y}-\mathrm{TZP} \\
\bar{x}( \pm \mathrm{SD})\end{array}$ & $\begin{array}{c}\text { Co-Cr } \\
\bar{x}( \pm \mathrm{SD})\end{array}$ & $\begin{array}{c}\mathrm{Ni}-\mathrm{Cr} \\
\bar{x}( \pm \mathrm{SD})\end{array}$ & $\mathrm{pV}$ \\
\hline Premolar abutment & $52.02(24.20)$ & $77.60(32.55)$ & 73.87 (21.49) & 0.404 \\
\hline Molar abutment & $96.98(17.13)$ & $93.26(43.39)$ & $79.03(18.05)$ & 0.597 \\
\hline Single abutment & $57.72(11.21)$ & $44.12(15.96)$ & $40.40(16.38)$ & 0.262 \\
\hline Single abutment & $79.24(17.01)$ & $63.15(22.38)$ & $60.69(26.21)$ & 0.488 \\
\hline Point D & $\begin{array}{c}\text { Y-TZP } \\
\bar{x}( \pm \mathrm{SD})\end{array}$ & $\begin{array}{c}\mathrm{Co}-\mathrm{Cr} \\
\bar{x}( \pm \mathrm{SD})\end{array}$ & $\begin{array}{c}\mathrm{Ni}-\mathrm{Cr} \\
\bar{x}( \pm \mathrm{SD})\end{array}$ & $\mathrm{pV}$ \\
\hline Premolar abutment & $45.94(8.05)$ & $46.42(17.61)$ & $40.75(10.56)$ & 0.743 \\
\hline Molar abutment & $60.02(9.48)$ & $53.66(18.87)$ & $64.11(18.28)$ & 0.600 \\
\hline Single abutment & $56.74(29.73)$ & $36.51(13.09)$ & $50.27(6.92)$ & 0.292 \\
\hline Single abutment & $58.48(22.72)$ & $48.18(26.27)$ & $35.70(21.53)$ & 0.427 \\
\hline
\end{tabular}

$(P<0.05)$. The best fit-independent of the different parameters-was at points A and D for the SLM technique and at points $\mathrm{B}$ and $\mathrm{C}$ for the lost-wax technique. The mean marginal discrepancy was $47.56 \mu \mathrm{m}$ for the Ni-Cr alloy, $55.6 \mu \mathrm{m}$ for $\mathrm{Y}$ TZP, and $43.92 \mu \mathrm{m}$ for the Co-Cr alloy. The mean internal gap was $54.11 \mu \mathrm{m}$ for the Ni-Cr alloy, $74.73 \mu \mathrm{m}$ for Y-TZP, and $58.76 \mu \mathrm{m}$ for the Co-Cr alloy. ANOVA revealed statistically significant differences $(P<0.05)$ in marginal and internal adaptations among the groups at the four measurement points.

\section{Discussion}

RP technology has attracted enormous interest among researchers because it greatly facilitates the realization of bespoke three-dimensional (3D) objects. A focused highpower laser beam can selectively melt layers of metal alloy powder in a mass using thermal energy and so can be used to produce any desired 3D object under computer control. After each section is scanned, the thickness of the powder bed of an alloy of the base metal is lowered by one layer, and a new layer of metal-based alloy is applied on top. This process is repeated until the part is completed.

In addition, the remaining unprocessed powder can be reused, in contrast with conventional methods in which most of the material is wasted and there are spatial limitations restricting the production of complex shapes [44]. SLM technology is characterized by remarkable precision, the possibility of building virtually any required dental geometry, and a constant surface speed and therefore a high-quality milling (especially of undercuts) thanks to the availability of four-axis simultaneous milling.

The optimal clinical marginal gap remains controversial. McLean and von Fraunhofer [44] found that a prosthetic restoration is successful if the marginal gap is less than $120 \mu \mathrm{m}$. Based on this criterion as the limit of clinical acceptance, the mean marginal and internal discrepancy values were clinically acceptable in all three groups in the present study.

While further research is necessary to optimize the process parameters and clinical applications, the laser-assisted RP procedure reported herein provides an efficient and rapid method for digitally designing and manufacturing complex metal structures for FDPs. It should be noted that many of the samples exhibited wide variations of the marginal gap; for example, while one surface was accurate to a few microns, there were large openings on the contralateral side. This may have been due to small displacements of the structure during corrections, which could have resulted in incomplete seating of the substructure and the largest marginal openings, 
or there may have been inaccuracies during cutting. All restorations were evaluated after the corrections had been made by the dental laboratory. Since the master model was duplicated in numerous resin models, there were many variables that could potentially change the results during the laboratory work, including the duplication time, small changes in water/powder ratio, water temperature, and wax distortion. In this study all of the substructures were placed and cemented in their respective resin models to test the differences between the different manufacturing techniques and the different materials used at the levels of the marginal gap and shoulder area.

The study was subject to several limitations.

(1) All structures were adapted using a standardized protocol, and retouching was performed by the same technician in order to avoid large inaccuracies.

(2) There was a possibility of samples being damaged during the cutting process. This risk was minimized but cutting under a water spray and using low feeding rates.

(3) All samples were produced and tested under ideal conditions, which might not accurately reflect typical clinical use.

(4) If the position of the framework was incomplete, the structure was adapted manually by technician using a standardized protocol with a margin of human error.

\section{Conclusion}

This study investigated the application of different techniques for the manufacture of FDPs. Within the limitations of this in vitro study, the following conclusions can be drawn.

(1) Copings produced with SLM technology have better marginal adaptation within an acceptable range.

(2) The type of metal alloy did not significantly affect the measurements.

(3) The marginal and shoulder areas presented greater discrepancies in values between metal alloys and YTZP.

(4) The cement gap was wider in the region of the shoulder than at the point of closure.

(5) All of the techniques and materials tested resulted in acceptable marginal openings in vitro.

The RP technique is a substantial innovation for the manufacture of dental prostheses, allowing dentists to work more easily and faster while still ensuring the production of a highquality finished product, due to significantly decreases in the risk of human error. It was concluded that, within the limitations of this study, the RP system can compete with conventional systems and can achieve a good marginal fit in vitro.

\section{Conflict of Interests}

The authors declare that there is no conflict of interests regarding the publication of this paper.

\section{Acknowledgments}

This study was supported by Dentsply Italy S.r.l. The authors are grateful to CNIS (Research Center for Nanotechnology Applied to Engineering) of "Sapienza" University of Rome, for its kind help in the analysis of samples by FESEM.

\section{References}

[1] N. U. Zitzmann, E. Hagmann, and R. Weiger, "What is the prevalence of various types of prosthetic dental restorations in Europe?" Clinical Oral Implants Research, vol. 18, no. 3, pp. 20 33, 2007.

[2] T. Miyazaki and Y. Hotta, "CAD/CAM systems available for the fabrication of crown and bridge restorations," Australian Dental Journal, vol. 56, supplement 1, pp. 97-106, 2011.

[3] D. Orstavik, P. Arneberg, and J. Valderhaug, "Bacterial growth on dental restorative materials in mucosal contact," Acta Odontologica Scandinavica, vol. 39, no. 5, pp. 267-274, 1981.

[4] J. Valderhaug, "Periodontal conditions and carious lesions following the insertion of fixed prostheses: a 10-year follow-up study," International dental journal, vol. 30, no. 4, pp. 296-304, 1980.

[5] C. Besimo, C. Jeger, and R. Guggenheim, "Marginal adaptation of titanium frameworks produced by CAD/CAM techniques," International Journal of Prosthodontics, vol. 10, no. 6, pp. 541546, 1997.

[6] K. W. Boening, M. H. Walter, and P. D. Reppel, "Non-cast titanium restorations in fixed prosthodontics," Journal of Oral Rehabilitation, vol. 19, no. 3, pp. 281-287, 1992.

[7] B. Fransson, G. Øilo, and R. Gjeitanger, "The fit of metalceramic crowns, a clinical study," Dental Materials, vol. 1, no. 5, pp. 197-199, 1985.

[8] Y. Kokubo, Y. Nagayama, M. Tsumita, C. Ohkubo, S. Fukushima, and P. V. von Steyern, "Clinical marginal and internal gaps of In-Ceram crowns fabricated using the GN-I system," Journal of Oral Rehabilitation, vol. 32, no. 10, pp. 753-758, 2005.

[9] A. F. Quintas, F. Oliveira, and M. A. Bottino, "Vertical marginal discrepancy of ceramic copings with different ceramic materials, finish lines, and luting agents: an in vitro evaluation," Journal of Prosthetic Dentistry, vol. 92, no. 3, pp. 250-257, 2004.

[10] Y. Kokubo, C. Ohkubo, M. Tsumita, A. Miyashita, P. V. von Steyern, and S. Fukushima, "Clinical marginal and internal gaps of Procera AllCeram crowns," Journal of Oral Rehabilitation, vol. 32, no. 7, pp. 526-530, 2005.

[11] F. Beuer, H. Aggstaller, J. Richter, D. Edelhoff, and W. Gernet, "Influence of preparation angle on marginal and internal fit of CAD/CAM-fabricated zirconia crown copings," Quintessence International, vol. 40, no. 3, pp. 243-250, 2009.

[12] K. W. Boening, B. H. Wolf, A. E. Schmidt, K. Kästner, and M. H. Walter, "Clinical fit of Procera AllCeram crowns," Journal of Prosthetic Dentistry, vol. 84, no. 4, pp. 419-424, 2000.

[13] K. B. May, M. M. Russell, M. E. Razzoog, and B. R. Lang, "Precision of fit: the Procera AllCeram crown," The Journal of Prosthetic Dentistry, vol. 80, no. 4, pp. 394-404, 1998. 
[14] M. Molin and S. Karlsson, "The fit of gold inlays and three ceramic inlay systems. A clinical and in vitro study," Acta Odontologica Scandinavica, vol. 51, no. 4, pp. 201-206, 1993.

[15] K. Quante, K. Ludwig, and M. Kern, "Marginal and internal fit of metal-ceramic crowns fabricated with a new laser melting technology," Dental Materials, vol. 24, no. 10, pp. 1311-1315, 2008.

[16] P. Vigolo and F. Fonzi, "An in vitro evaluation of fit of zirconiumoxide-based ceramic four-unit fixed partial dentures, generated with three different CAD/CAM systems, before and after porcelain firing cycles and after glaze cycles," Journal of Prosthodontics, vol. 17, no. 8, pp. 621-626, 2008.

[17] L. Jahangiri, C. Wahlers, E. Hittelman, and P. Matheson, "Assessment of sensitivity and specificity of clinical evaluation of cast restoration marginal accuracy compared to stereomicroscopy," The Journal of Prosthetic Dentistry, vol. 93, no. 2, pp. 138-142, 2005.

[18] R. Mejia and S. M. Tobon, "Marginal fit of metal ceramic restorations subjected to a standardized postsoldering technique," The Journal of Prosthetic Dentistry, vol. 83, no. 5, pp. 535539, 2000.

[19] P. Limkangwalmongkol, G. J. Chiche, and M. B. Blatz, "Precision of fit of two margin designs for metal-ceramic crowns: basic science research," Journal of Prosthodontics, vol. 16, no. 4, pp. 233-237, 2007.

[20] L. V. Foster, "Failed conventional bridge work from general dental practice: clinical aspects and treatment needs of 142 cases," British Dental Journal, vol. 168, no. 5, pp. 199-201, 1990.

[21] R. A. Giordano, "Dental ceramic restorative systems," Compendium of Continuing Education in Dentistry, vol. 17, no. 8, pp. 779-794, 1996.

[22] K. J. Anusavice, Phillips' Science of Dental Materials, Elsevier, Philadelphia, Pa, USA, 11th edition, 2003.

[23] Y. Ucar, Z. Aksahin, and C. Kurtoglu, "Metal ceramic bond after multiple castings of base metal alloy," The Journal of Prosthetic Dentistry, vol. 102, no. 3, pp. 165-171, 2009.

[24] G. H. L. Lombardo, R. S. Nishioka, R. O. A. Souza et al., "Influence of surface treatment on the shear bond strength of ceramics fused to cobalt-chromium," Journal of Prosthodontics, vol. 19, no. 2, pp. 103-111, 2010.

[25] N. Samet, B. Resheff, S. Gelbard, and N. Stern, "A CAD/CAM system for the production of metal copings for porcelain-fusedto-metal restorations," The Journal of Prosthetic Dentistry, vol. 73, no. 5, pp. 457-463, 1995.

[26] T. Miyazaki, Y. Hotta, J. Kunii, S. Kuriyama, and Y. Tamaki, "A review of dental CAD/CAM: current status and future perspectives from 20 years of experience," Dental Materials Journal, vol. 28, no. 1, pp. 44-56, 2009.

[27] F. Duret, J. L. Blouin, and B. Duret, "CAD-CAM in dentistry," The Journal of the American Dental Association, vol. 117, no. 6, pp. 715-720, 1988.

[28] E. D. Rekow, "Dental CAD/CAM systems: a 20-year success story," The Journal of the American Dental Association, vol. 137, no. 9, pp. 5S-6S, 2006.

[29] J.-G. Wittneben, R. F. Wright, H.-P. Weber, and G. O. Gallucci, "A systematic review of the clinical performance of CAD/CAM single-tooth restorations," The International Journal of Prosthodontics, vol. 22, no. 5, pp. 466-471, 2009.

[30] S. Harder and M. Kern, "Survival and complications of computer aided-designing and computer-aided manufacturing vs. conventionally fabricated implant-supported reconstructions: a systematic review," Clinical Oral Implants Research, vol. 20, no. 4, pp. 48-54, 2009.
[31] J. R. Kelly, "Developing meaningful systematic review of CAD/CAM reconstructions and fiber-reinforced composites," Clinical Oral Implants Research, vol. 18, supplement 3, pp. 205217, 2007.

[32] R. O. A. Souza, M. Özcan, C. A. Pavanelli et al., "Marginal and internal discrepancies related to margin design of ceramic crowns fabricated by a CAD/CAM system," Journal of Prosthodontics, vol. 21, no. 2, pp. 94-100, 2012.

[33] K.-B. Lee, C.-W. Park, K.-H. Kim, and T.-Y. Kwon, "Marginal and internal fit of all-ceramic crowns fabricated with two different CAD/CAM systems," Dental Materials Journal, vol. 27, no. 3, pp. 422-426, 2008.

[34] F. Beuer, J. Schweiger, M. Eichberger, H. F. Kappert, W. Gernet, and D. Edelhoff, "High-strength CAD/CAM-fabricated veneering material sintered to zirconia copings-a new fabrication mode for all-ceramic restorations," Dental Materials, vol. 25, no. 1, pp. 121-128, 2009.

[35] F. Beuer, H. Aggstaller, D. Edelhoff, W. Gernet, and J. Sorensen, "Marginal and internal fits of fixed dental prostheses zirconia retainers," Dental Materials, vol. 25, no. 1, pp. 94-102, 2009.

[36] S. Witkowski, F. Komine, and T. Gerds, "Marginal accuracy of titanium copings fabricated by casting and CAD/CAM techniques," Journal of Prosthetic Dentistry, vol. 96, no. 1, pp. 47$52,2006$.

[37] F. Beuer, H. Aggstaller, D. Edelhoff, and W. Gernet, "Effect of preparation design on the fracture resistance of zirconia crown copings," Dental Materials Journal, vol. 27, no. 3, pp. 362-367, 2008.

[38] F. Beuer, D. Edelhoff, W. Gernet, and J. A. Sorensen, “Threeyear clinical prospective evaluation of zirconia-based posterior fixed dental prostheses (FDPs)," Clinical Oral Investigations, vol. 13, no. 4, pp. 445-451, 2009.

[39] A. Örtorp, D. Jönsson, A. Mouhsen, and P. Vult von Steyern, "The fit of cobalt-chromium three-unit fixed dental prostheses fabricated with four different techniques: a comparative in vitro study," Dental Materials, vol. 27, no. 4, pp. 356-363, 2011.

[40] A. H. L. Tjan, T. Li, G. Irving Logan, and L. Baum, "Marginal accuracy of complete crowns made from alternative casting alloys," The Journal of Prosthetic Dentistry, vol. 66, no. 2, pp. 157$164,1991$.

[41] K. Torabi Ardekani, A. H. Ahangari, and L. Farahi, "Marginal and internal fit of CAD/CAM and slip-cast made zirconia copings," Journal of Dental Research, Dental Clinics, Dental Prospects, vol. 6, no. 2, pp. 42-48, 2012.

[42] P. Proussaefs, "Crowns cemented on crown preparations lacking geometric resistance form. Part II: effect of cement," Journal of Prosthodontics, vol. 13, no. 1, pp. 36-41, 2004.

[43] J. P. Kruth, L. Froyen, J. van Vaerenbergh, P. Mercelis, M. Rombouts, and B. Lauwers, "Selective laser melting of ironbased powder," Journal of Materials Processing Technology, vol. 149, no. 1-3, pp. 616-622, 2004.

[44] J. W. McLean and J. A. von Fraunhofer, "The estimation of cement film thickness by an in vivo technique," British Dental Journal, vol. 131, no. 3, pp. 107-111, 1971. 

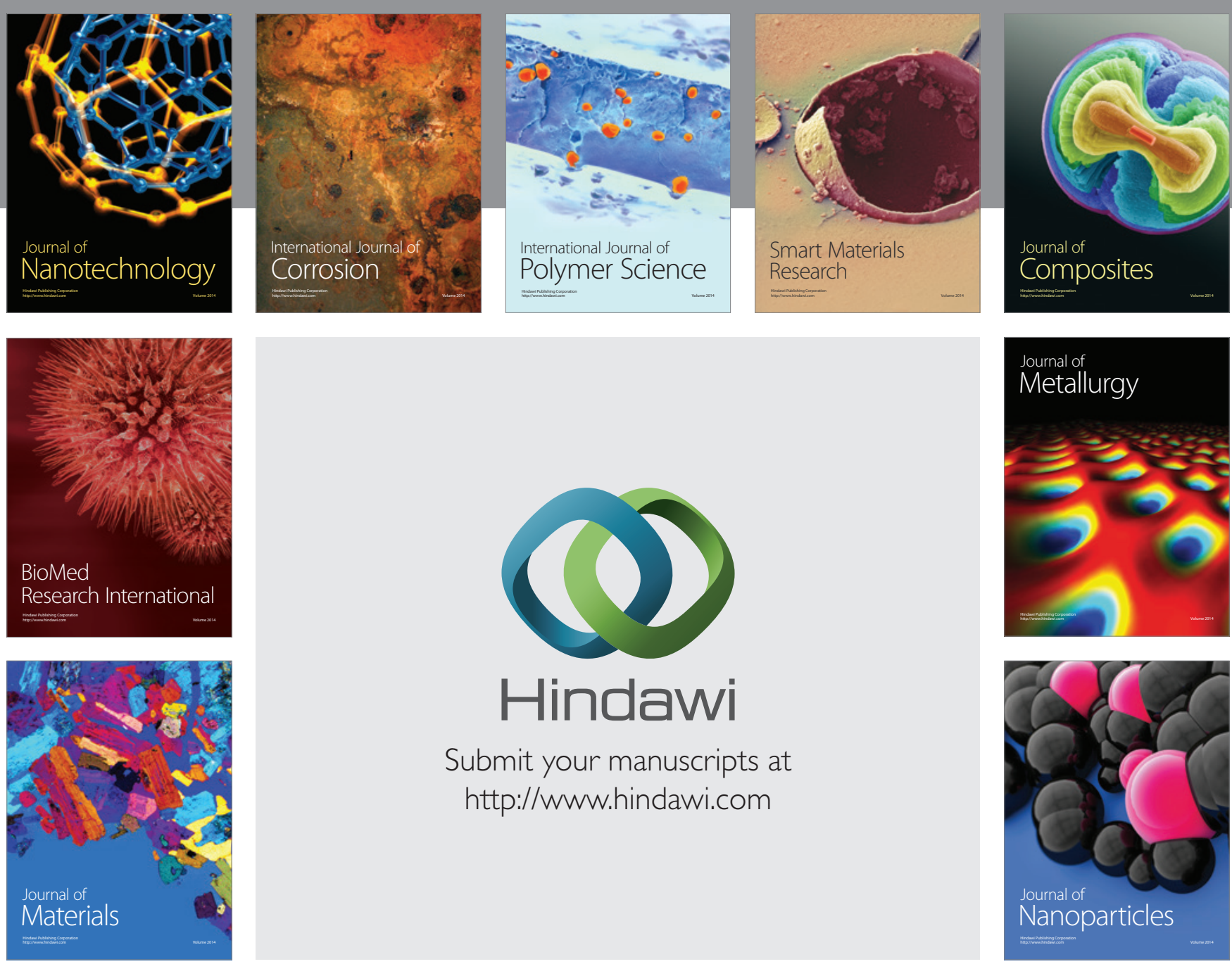

Submit your manuscripts at http://www.hindawi.com
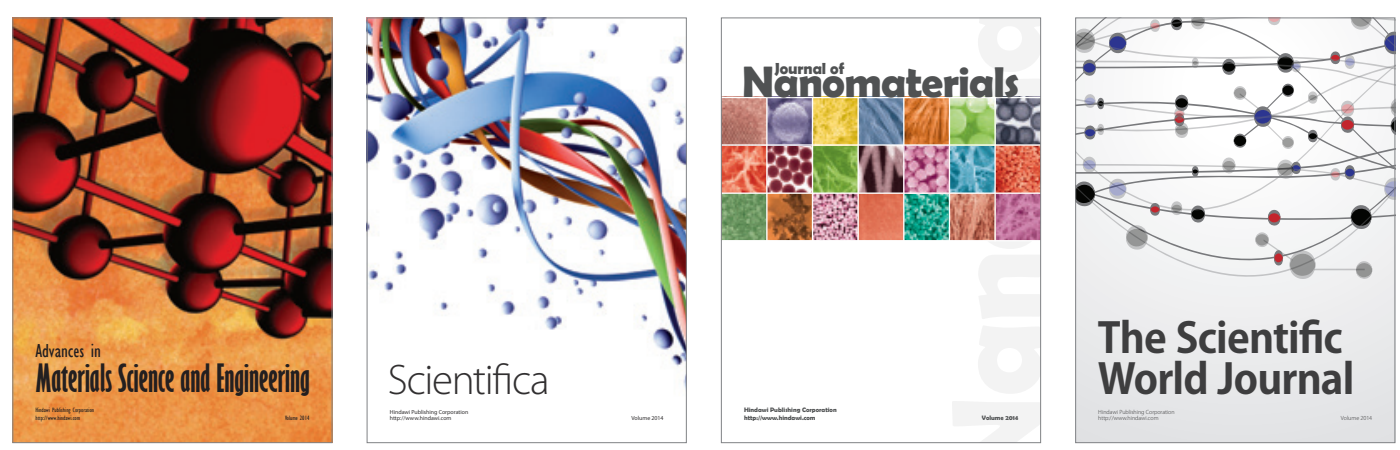

\section{The Scientific World Journal}
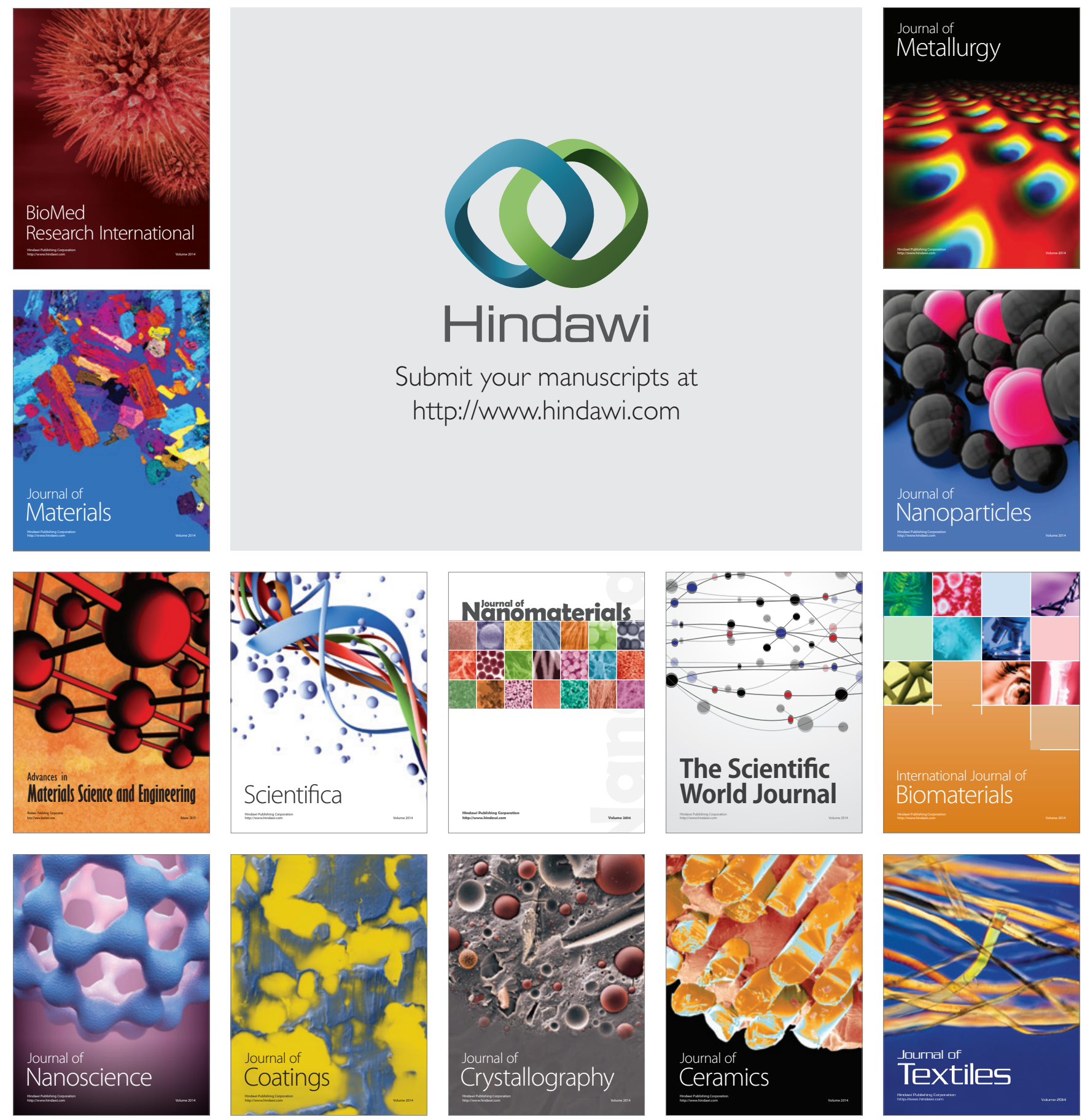